\title{
Experimental assessment of tidal turbine loading from irregular waves over a tidal cycle
}

\author{
Samuel Draycott ${ }^{1} \mathbb{D} \cdot$ Jeffrey Steynor ${ }^{1} \cdot$ Anup Nambiar $^{1} \cdot$ Brian Sellar $^{1} \cdot$ Vengatesan Venugopal $^{1}$
}

Received: 19 October 2018 / Accepted: 20 May 2019 / Published online: 3 June 2019

(c) The Author(s) 2019

\begin{abstract}
Waves interact with currents in tidal channels with the resulting wave-current environment largely determining the loads experienced by tidal stream turbines. Over a tidal cycle, the magnitude and direction of the current velocity changes and hence so does the combined wave-current conditions the turbines must operate within. Here we demonstrate this effect experimentally, generating a realistic irregular wave case in both following (in the same direction as the waves) and opposing currents prior to assessing the resulting loads on a fully instrumented 1:15 scale tidal turbine model aligned with the current direction. Large changes in the environmental conditions, along with the turbine performance and loads, are demonstrated through the presentation of temporal, spectral and statistical outputs. The experimental results demonstrate that the full-scale equivalent significant wave height changes from $2.25 \mathrm{~m}$ in zero current to $6.11 \mathrm{~m}$ in $3.2 \mathrm{~m} / \mathrm{s}$ opposing current and $1.56 \mathrm{~m}$ in $3.2 \mathrm{~m} / \mathrm{s}$ following current. The corresponding standard deviations of measured turbine parameters for the opposing condition range between 215 and $260 \%$ of the following case, and between 340 and $565 \%$ of the current-only measurements. Hence, when waves are present, significantly greater fatigue damage will be accumulated during one-half of the tidal cycle. The mean values, however, appear to be unaffected by the presence of waves suggesting that the overall turbine performance is unaltered. These results demonstrate the requirement to understand the combined wave-current environment and to test and de-risk tidal stream turbines for operation in both following and opposing wave-current conditions. Significant additional insight is gained into the nature of loads experienced by tidal turbines in irregular wave conditions, a scarcely documented phenomenon.
\end{abstract}

Keywords Tidal stream turbine $\cdot$ Wave loading · Irregular waves · Wave-current interaction

\section{Introduction}

For tidal stream turbines (TSTs) to become a commercially viable technology, they must maintain high levels of reliability in the hostile ocean environment. Consequently, it is a requirement to ensure they can withstand large unsteady hydrodynamic loads introduced by the presence of waves, turbulence and velocity shear (Milne et al. 2010, 2017; MacEnri et al. 2013). Of these, the peak loads induced by waves has been suggested to be most significant and can be several orders of magnitude larger than ambient turbulence (Lust et al. 2013).

Samuel Draycott

S.Draycott@ed.ac.uk

1 School of Engineering Institute for Energy Systems, The University of Edinburgh, Edinburgh EH9 3DW, UK
It is generally accepted that unsteady wave action on device loading and power production must be considered when the averaged orbital velocities are greater than $20 \%$ of the rated current speed (IEC TS 62600-200:2013 2013; IEC TS 62600-201:2015 2015). There have been a variety of published numerical and experimental studies assessing the influence of waves on tidal turbines. Although there are a few numerical studies on irregular wave loads (Milne et al. 2010; Mullings et al. 2017), experimental works have largely been limited to the assessment of monochromatic 'regular' waves. This is despite the fact that real ocean waves can seldom be classified as regular.

Possibly, the first documented experimental study on the effect of regular waves on tidal turbines was presented in Barltrop et al. (2006). Results from this experiment, along with those presented in Galloway et al. (2014) and Faudot and Dahlhaug (2012), were used to validate blade element momentum theory (BEMT) codes including the presence of 
waves. Wave-induced variations in power and thrust have been further reported in Gaurier et al. (2013), De Jesus Henriques et al. (2014), Martinez et al. (2018), with additional studies discussing the influence of wave phase and turbine depth (Lust et al. 2013; Luznik et al. 2013). A general consensus arises from the literature that although the mean values of the power and thrust remain similar in the presence of waves, the wave-induced variations of these parameters can be very significant (Gaurier et al. 2013; Draycott et al. 2019a).

When undertaking scaled experiments, care must be taken to ensure that the results are representative of those expected for a full-scale tidal turbine. One of the major considerations, due to operating at lower flow velocities, is the reduced Reynolds number $(R e)$. It is therefore important that the model scale and corresponding flow velocities are large enough that Re independence has been obtained for both the lift and drag coefficients (Lust et al. 2013; Luznik et al. 2013), so that small changes in inflow velocity do not result in unrepresentative performance alterations. In addition, it may be necessary to modify the blade geometry to obtain the correct power and thrust coefficients in the reduced Re regime (Whelan and Stallard 2011). Another key consideration is the control strategy. Although it is typical to use speed control for experimental tests [e.g. Guo et al. (2018), Payne et al. (2018), Martinez et al. (2018)], and is used in this current study, consideration must be given to the likely full-scale control strategy. For example, preliminary studies on tidal turbine control show that the implementation of torque control could significantly alter the expected peak thrust (Ordonez-Sanchez et al. 2019).

Although there is mention in Gaurier et al. (2013) that a comparison of their results to irregular wave equivalents would be interesting, at present, there are very limited published experimental studies which assess the influence of tidal turbine loads in irregular wave conditions. Stallard et al. (2013) presents experiments carried out in irregular waves; however, the focus of the study was on the effect of wave forcing on wake recovery, and as such there is little detail on the turbine loads experienced in such conditions. In Sos et al. (2017), variations in power and thrust coefficient are reported for a single irregular sea state obtained from towing tank experiments.

In this paper, we investigate the difference in loads experienced at the extremes of the tide: assessing the expected loads at representative peak ebb and flood velocities with a constant 'open-ocean' irregular wave condition. Such investigations are required to asses the criticality of conducting synchronised wave and tidal resource characterisations, and to extend understanding of the turbine behaviour from regular waves [e.g. Draycott et al. (2019a)] to realistic irregular conditions. The environmental conditions of this experimental campaign are analogous to those experienced by a tidal turbine which is able to yaw into the current direction, dur- ing a storm that spans one entire tidal cycle. The effect of the different current directions will significantly alter the wave kinematics and hence the corresponding TST loads. Indeed, in Hashemi et al. (2016) it is noted that a $60 \%$ increase in significant wave height, $H_{m 0}$, is expected for $2 \mathrm{~m} / \mathrm{s}$ opposing current, and a $20 \%$ reduction in $H_{m 0}$ is expected for the equivalent following current (peak period, $T_{\mathrm{p}},=8 \mathrm{~s}$ ). To assess the consequence of the wave-current interaction on TST loading, in this paper we experimentally simulate a single 'zerocurrent' full-scale spectral wave condition $\left(H_{m 0}=2.25 \mathrm{~m}\right.$, $T_{\mathrm{P}}=9.7 \mathrm{~s}$ ) with $\pm 3.2 \mathrm{~m} / \mathrm{s}$ current velocity, corresponding to representative maximum and minimum velocities over a diurnal tidal cycle. Experiments are carried out at the 1:15 scale at the FloWave Ocean Energy Research Facility, and resulting loads on a scale model of a bottom-mounted horizontal axis tidal turbine are presented.

The paper is laid out as follows. The methodology, including wave-current theory, test setup, and condition definition are presented in Sect. 2. The results of the measured environmental conditions, along with TST loads and power, are presented in Sect. 3: focusing on time-domain, spectral and statistical assessment. Further discussion is presented in Sect. 4 with concluding remarks offered in Sect. 5.

\section{Methodology}

\subsection{The influence of current on wave properties}

Tidal currents alter the form of waves, including the wave height, wavelength and associated velocities. These changes can significantly alter the wave kinematics and hence the loading on TST devices.

Wave-current interaction theory often uses a quantity termed wave action, as it is assumed to be conserved through wave-current interaction. The conservation of wave action is described in Jonsson (1990) by:

$$
\frac{\partial}{\partial x}\left(\frac{E\left(C_{g r}+U \cos \beta\right)}{\omega_{r}}\right)=0,
$$

where $U$ is the current velocity, $x$ is the horizontal co-ordinate in an axis parallel to the wave propagation direction, $E$ is the wave energy, and $\beta$ is the relative angle between the wave and current fields. The subscript $r$ defines values relative to the current field, and hence $\omega_{r}$ and $C_{g r}$ are the angular wave frequency and group velocity, respectively, observed from a reference moving at the same velocity as the current. These are defined in Eqs. (2) and (3).

$$
\begin{aligned}
\omega_{r} & =\sqrt{g k \tanh k h}, \\
C_{g r} & =\frac{1}{2} \frac{\omega_{r}}{k}\left(1+\frac{2 k h}{\sinh 2 k h}\right)
\end{aligned}
$$


where $g$ is the acceleration due to gravity, $h$ is the water depth, and the wavenumber, $k$, is defined as a function of angular frequency, $\omega$, by Eq. (4):

$\omega-k U \cos \beta=\sqrt{g \tanh k h}$.

Noting that frequency, $f$, dependent wave energy $E(f)=$ $\rho g S_{\eta}(f)$, a frequency-dependent wave-action (WA) term (Draycott et al. 2018) can be defined:

$W A(f)=\frac{\rho g S_{\eta}(f)}{\omega_{r}(f)}\left[C_{g r}(f)+U \cos \beta\right]$,

where $\rho$ is the density, and $S_{\eta}(f)$ the wave energy spectrum density. Equation (5) is only valid under the assumption that wave blocking does not occur for the wave frequency and current velocity combination being modelled [see Moreira and Peregrine (2012) for details]. This will occur when an opposing current velocity exceeds the stopping velocity: the point at which the wave group velocity is zero in the stationary reference frame (Hashemi et al. 2016). In addition, it is required to assume that there is no transfer of energy between wave frequencies during the wave modification by current [as in Chakrabarti and Johnson (1995)]. Under these assumptions, $W A(f)$ can be assumed constant, and Eq. (5) can be used to model the change in $S_{\eta}(f)$ with $U$; and key spectral parameters such as $H_{m 0}$ can be calculated utilising spectral moments, $m_{n}$, of the energy density spectrum:

$H_{m 0}=4 \sqrt{m_{0}}$,

where $m_{n}=\int_{0}^{\infty} S_{\eta}(f) f^{n} \mathrm{~d} f$.

Equations (5) and (6) can then be used to compare the theoretical changes in spectral parameters to those measured during the experimental test programme. An example of the effect of current on the wave properties is depicted in Fig. 1 for current opposing waves. The change in both wave height and wavelength is shown, and the regions of no current and current are highlighted. As the current opposes the waves, the wave height and wavenumber increase whilst group velocity decreases.

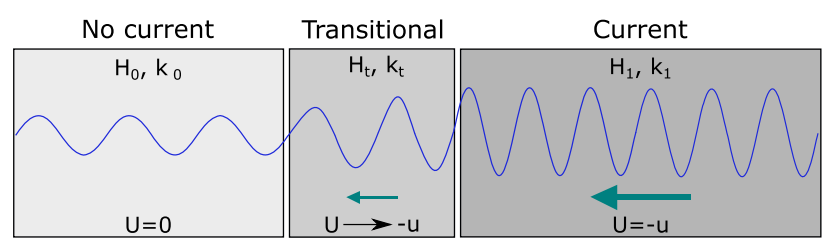

Fig. 1 Diagram showing wave propagating from the region of no current to a region with current. The change in wave height and wavelength (wavenumber) due to interaction with the current field indicated. Example shown with opposing current (negative U) where wave height increases and wavelength decreases. (Draycott et al. 2018)
Of importance for the loads on tidal turbines is the subsequent effect on the horizontal wave-induced velocities, $U_{w}$, in the $z$ range occupied by the rotor plane. The frequency and depth-dependent amplitudes of the wave-induced velocity, $U_{w}(f, z)$, to leading order, is:

$U_{w}(f, z)=\frac{g A(f) k(f)}{w_{r}(f)} \frac{\cosh (k(f)(z+h))}{\cosh (k(f) h)}$,

where $A(f)$ is the frequency-dependent amplitudes of the surface elevation. Noting that $S_{\eta}(f) \propto A(f)^{2}$, the horizontal wave-induced velocity spectra can be expressed as:

$S_{U_{w}}(f, z)=\frac{g^{2} k^{2}(f)}{w_{r}^{2}(f)} \frac{\cosh ^{2}(k(f)(z+h))}{\cosh ^{2}(k(f) h)} S_{\eta}(f)$.

$\int_{0}^{\infty} S_{U_{w}}(f, z) \mathrm{d} f$ is the total variance in the horizontal velocity attributed to waves at $z$, noting that roughly turbine power $P \propto U^{3}$ and thrust $T \propto U^{2}$. From Eqs. (5) and (6), it is evident that $S_{\eta}(f)$ and $H_{m 0}$ will be larger when waves oppose the current $\left(\beta=180^{\circ}\right)$, whilst from Eq. (4) it is can be inferred that the wavenumber will also increase in opposing scenarios. Assessing Eq. (8), it is then clear that in opposing conditions wave-induced velocities will be larger near the surface yet the rate of vertical attenuation of wave-induced velocity will be greater. Turbines placed relatively close to the surface will therefore experience larger variations in loads and power in opposing conditions, yet those in very deep water or installed low in the water column may experience larger loads in the following conditions (sea state dependent).

\subsection{Test setup}

\subsubsection{The model turbine}

The model scale TST, including blade geometry and installed instrumentation, is well described in Payne et al. (2017), with external geometry files and baseline turbine data available for download at https://doi.org/10.7488/ds/1707. As a result, only a short description is provided here. The TST model has been designed to correspond to the majority of full-scale prototypes (see Parkinson and Collier 2016; MeyGen Ltd. 2016) and as such is a bottom mounted machine with a threebladed horizontal axis rotor. The design is 1:15 scale, with a rotor diameter, $D$, of $1.2 \mathrm{~m}$ with the rotor axis $1 \mathrm{~m}$ from the bed. Load sensors measure streamwise root bending moment, $\mathrm{RBM}$, for each blade, along with torque, $Q$, and thrust, $\mathrm{T}$, on the whole rotor. The generator is simulated by a brushless permanent magnet servo motor, which is connected to the rotor shaft in 'direct drive' fashion. Rotor angular position, $\theta$, is obtained from the motor encoder.

To ensure full-scale similitude, the blades are designed to provide a rotor thrust coefficient, $C_{\mathrm{T}}$, similar to a full-scale 
Table 1 Description of installed instrumentation including position relative to the turbine rotor plane centre

\begin{tabular}{|c|c|c|c|c|c|c|}
\hline \multirow[t]{2}{*}{ Type of instrumentation } & \multirow[t]{2}{*}{ Model } & \multirow[t]{2}{*}{ Variables measured } & \multirow[t]{2}{*}{ Sample rate $(\mathrm{Hz})$} & \multicolumn{3}{|c|}{ Rel. location (m) } \\
\hline & & & & $X$ & $Y$ & $Z$ \\
\hline $\mathrm{ADV}$ & Vectrino Profiler & $U, V, W$ & 100 & -2.40 & 0 & 0.60 \\
\hline Wave gauge & FloWave & $\eta$ & 128 & 0 & 0 & - \\
\hline TST instrumentation & UoE & $T, Q, \mathrm{RBM}, \theta$ & 256 & 0 & 0 & 0 \\
\hline Load cell & AMTI OR6-7 & $\begin{array}{l}F_{X}, F_{Y}, F_{Z} \\
M_{X}, M_{Y}, M_{Z}\end{array}$ & 256 & 0.49 & 0 & -1.00 \\
\hline
\end{tabular}

generic turbine across a wide range of tip-speed ratios, $\lambda$. At $0.8 \mathrm{~m} / \mathrm{s}$, the chord-length Reynolds numbers vary between $0.5 \times 10^{5}$ (root) and $2.5 \times 10^{5}$ (tip) (Draycott et al. 2019a). From previous experiments, the power and thrust coefficients $\left(C_{\mathrm{P}}\right.$ and $\left.C_{\mathrm{T}}\right)$ for the model turbine rotor are found to be Reynolds invariant above $0.6 \mathrm{~m} / \mathrm{s}$.

In this work, two points in the tidal cycle, with a nominal flow speed of $0.8 \mathrm{~m} / \mathrm{s}$, corresponding to the peak ebb and flood velocities have been simulated with a constant 'openocean' wave condition. Hence, in the tests presented, the motor was operated in speed control mode with a constant rotational velocity, $\omega$, of $9.42 \mathrm{rad} / \mathrm{s}(90 \mathrm{rpm})$, which results in a $\lambda$ value of 7 . This was the design $\lambda$ of the turbine at the flow speed used to maintain proper scaling of the thrust. Keeping the rotational speed of the turbine constant also helps isolate the influence of the waves and flow conditions on turbine power and loads. In real flow conditions at test or deployment sites, the rotational speed of the turbine would be modified based on the instantaneous flow velocities during a tidal cycle. This would be done to keep $\lambda$ constant for any flow velocity with the aim of maximising the power extracted by the turbine.

Note that equivalent full-scale environmental conditions and loads can be obtained using Froude scaling [see e.g. Heller (2011)] of the measured parameters. Due to the rotor size relative to the water depth $(1.2 \mathrm{~m}$ rotor in $2 \mathrm{~m}$ water depth), and the position of the rotor in the water column, wave-induced velocities and loads should be comparable to those experienced by the full-scale turbines installed at the MeyGen site [18 $\mathrm{m}$ rotor in $31 \mathrm{~m}$ water depth, (New Civil Engineer 2019)].

\subsubsection{The test facility}

The experimental work presented herein was carried out at the FloWave Ocean Energy Research Facility (FloWave, https://www.flowave.eng.ed.ac.uk), located at the University of Edinburgh (UoE), UK (Draycott et al. 2016). This facility is a circular, combined wave and current basin, with a diameter of $25 \mathrm{~m}$ and a nominal water depth of $2 \mathrm{~m}$. Owing to the circular design, there is no limitation on the direc- tion of either the wave or current fields, which enables the generation of waves at arbitrary angles to the current. For the presented work, this enables the following and opposing wave-current conditions to be generated without rotating the model or moving wave and current generating equipment. A diagrammatic representation of the FloWave facility can be found in Draycott et al. (2019a), depicting the flow generation mechanism and wavemaker configuration. It is worth noting that this arrangement does not provide the ability to control the turbulence intensity and is around $7 \%$ for the flow velocity used in these experiments. Details of the spatial variation of mean velocity and turbulence can be found in Sutherland et al. (2017a), Noble et al. (2015).

The blockage ratio, defined as the turbine rotor plane area relative to the tank cross-sectional area, is approximately $2.3 \%$. The horizontal and vertical blockage are significantly different: $D / h=0.6$ and $D / W=0.048$, where $W$ is the basin width. Due to the large horizontal dimension, and representative vertical dimension, any unrealistic blockage effects during the tests are not expected.

\subsubsection{Instrumentation and configuration}

In addition to the sensors integrated into the TST model (Sect. 2.2.1), further instrumentation was installed throughout the facility. A summary of all the installed instrumentation is presented in Table 1 . The additional instrumentation includes a resistance-type wave gauge to measure surface elevation, an acoustic Doppler velocimeter (ADV) to measure current velocity, and a bottom-mounted six-axes load cell to measure the total forces, $F$, and moments, $M$, on the entire TST structure (blades, TST body and tower). The test setup is illustrated in Fig. 2, where the turbine is depicted to scale in conjunction with the installed instrumentation.

\subsection{Wave-current conditions}

A single input wave spectrum has been defined representative of those seen at typical tidal sites (see e.g. Venugopal and Nemalidinne 2015). These have been generated in the presence of target current velocities of $\pm 3.1 \mathrm{~m} / \mathrm{s}$ correspond- 
Fig. 2 Side view of the location of test instrumentation in the FloWave basin relative to the rotor plane centre (dimensions in $\mathrm{mm}$ )

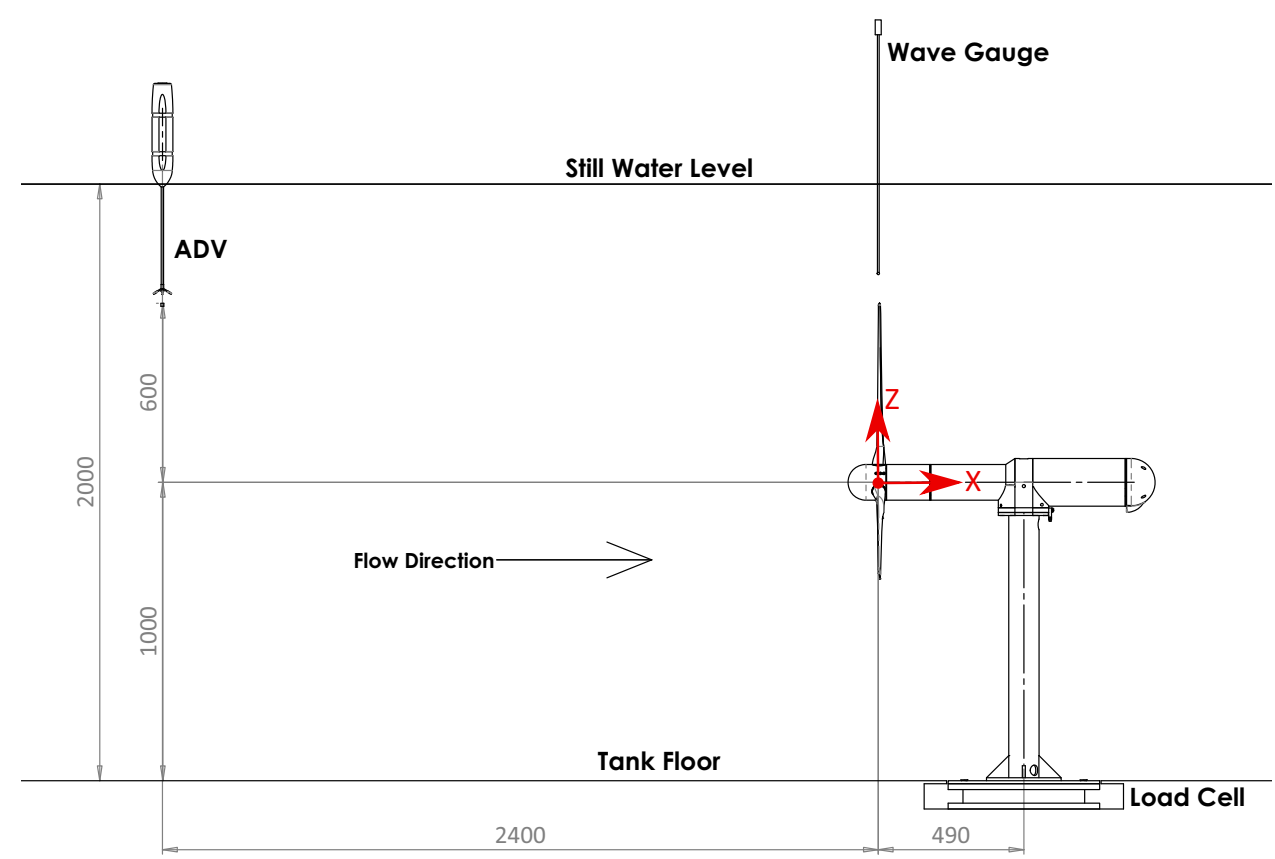

Table 2 Full-scale and tank-scale equivalent wave and current parameters for the following $(+)$ and opposing $(-)$ wave-current conditions tested

\begin{tabular}{|c|c|c|c|c|c|c|c|c|c|c|c|c|}
\hline & \multicolumn{6}{|c|}{ Full-scale } & \multicolumn{6}{|c|}{ Tank scale } \\
\hline & \multicolumn{2}{|c|}{ Input } & \multicolumn{2}{|c|}{ Expected } & \multicolumn{2}{|c|}{ Scaled measurement } & \multicolumn{2}{|c|}{ Input } & \multicolumn{2}{|c|}{ Expected } & \multicolumn{2}{|c|}{ Measured } \\
\hline & + & - & + & - & + & - & + & - & + & - & + & - \\
\hline$H_{m 0}(\mathrm{~m})$ & 2.25 & 2.25 & 1.61 & 5.55 & 1.56 & 6.11 & 0.15 & 0.15 & 0.107 & 0.392 & 0.104 & 0.408 \\
\hline$T_{\mathrm{P}}(\mathrm{s})$ & 9.68 & 9.68 & 9.71 & 9.43 & 9.97 & 9.18 & 2.5 & 2.5 & 2.51 & 2.41 & 2.57 & 2.37 \\
\hline$U(\mathrm{~m} / \mathrm{s})$ & 3.1 & -3.1 & 3.1 & -3.1 & 3.2 & -3.2 & 0.8 & -0.8 & 0.8 & -0.8 & 0.82 & -0.82 \\
\hline
\end{tabular}

Input wave conditions are defined along with their expected transformation in current from theory. The measured wave conditions are also provided. Both sea states were created using JONSWAP spectra with $\gamma$ set to 3.3

ing to common peak ebb and flood conditions at tidal sites (see e.g. Sellar et al. 2018) in which turbines operate at rated power. For example, the the Andritz Hydro Hammerfest turbine (Walker and Cappietti 2017) and the Alstom Ocean Energy's DEEP-Gen IV (McNaughton et al. 2015) both achieve rated power above $2.7 \mathrm{~m} / \mathrm{s}$. Simulating both following and opposing conditions enables the extent of the variation in turbine loads to be inferred over a typical tidal cycle and is representative of having a persistent open-ocean wave condition when the tidal current is varying in the channel.

The chosen conditions are defined in Table 2 and show the input wave and current conditions for both full-scale and tank-scale equivalence. Froude scaling has been used to obtain tank scale values for generation in the facility. $H_{m 0}, T_{\mathrm{P}}$, and the peak enhancement factor, $\gamma$, are presented. The values measured in the FloWave tank are also presented, along with the expected wave height and peak period (from peak of current modified wave spectrum) transformation in the two current velocities, calculated using Eqs. (5) and (6). Three repeats were carried out for each wave condition to assess the influence of turbulence on the repeatability of the tests. A test length of $545 \mathrm{~s}$ is implemented, with a $512 \mathrm{~s}$ repeat time. The final $512 \mathrm{~s}$ of each test was then used for analysis to ensure that the travelling wave components had arrived at the model location. This approach also ensures that an integer number of wave cycles have been been measured for every frequency component which improves the quality of spectral analysis.

Good agreement was found between the theoretical and measured parameters for the two sea states, as shown in Table 2. The full range of $H_{m 0}$ values expected for the modelled sea state (from Eq. (5)) over the hypothetical tidal cycle are presented in Fig. 3. It is worth noting that to compute these theoretical values, frequency components above $0.5 \mathrm{~Hz}(0.13 \mathrm{~Hz}$ full scale $)$ are omitted due to difficulties in numerically calculating wavenumbers for frequencies close to, or above, the blocking point (waves are blocked just above $0.5 \mathrm{~Hz}$ in $0.82 \mathrm{~m} / \mathrm{s}$ of current). In this figure, the measured values obtained at FloWave for the two current conditions are presented (as described in Table 2) showing reasonable agreement with linear theory. An additional point is also included, 


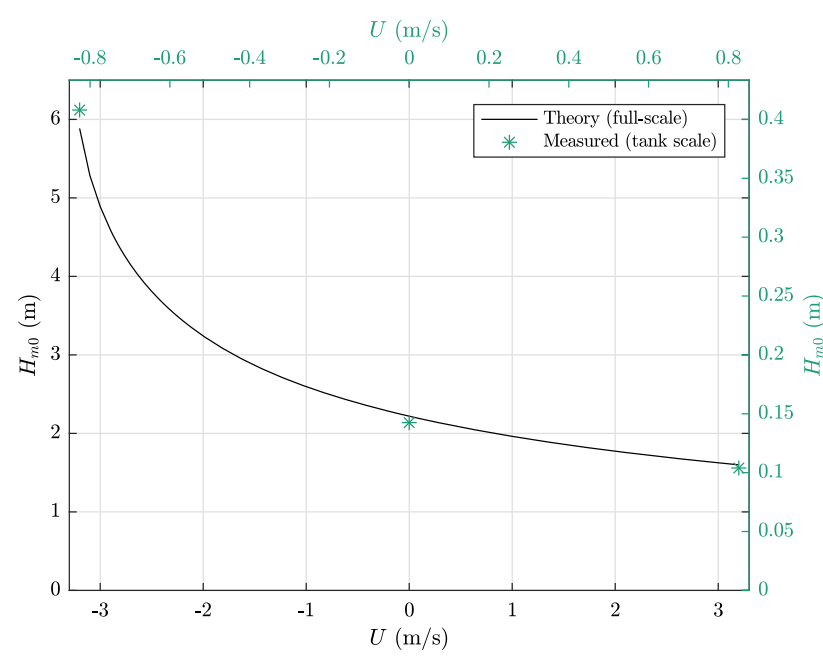

Fig. 3 Theoretical change in significant wave height as a function of current velocity for a full-scale input spectrum without current of $H_{m 0}=$ $2.25 \mathrm{~m}, T_{\mathrm{p}}=9.7 \mathrm{~s}$ and $\gamma=3.3$. The $1: 15$ scale measured $H_{m 0}$ values in FloWave are shown by the green markers and indicated by the second set of axes. The zero current condition is the expected $H_{m 0}$ value in FloWave (measured from a previous test campaign)

depicting the expected value of the no current spectral condition in FloWave obtained from a previous measurement campaign without the turbine installed. The large expected and measured variation in $H_{m 0}$ over the tidal cycle is evident, highlighting the significant effect of these fast current velocities on concurrent wave fields.

\section{Results}

Environmental conditions, along with the resulting effect on key turbine parameters, are presented here for both the following and opposing wave conditions. Time-domain results, including repeatability, are presented in Sect. 3.1, with equivalent frequency domain results discussed in Sect. 3.2. An assessment of the statistics of the wave-induced load variations for the two wave cases is additionally presented in Sect. 3.3.

As detailed in Sect. 2.2.3, a large number of sensors are deployed during the tests, and as such to practically present the results only key parameters are graphically presented. A consistent set of parameters are used throughout the results section:

1. $\eta$ : surface elevation (m);

2. $U$ : streamwise velocity, $2 \mathrm{D}$ upstream $0.4 \mathrm{~m}$ beneath the surface $(\mathrm{m} / \mathrm{s})$;

3. $\mathrm{RBM}_{0}$ : one of the streamwise blade root bending moment sensors $(\mathrm{Nm})$;

4. $T$ : rotor-based thrust measurement $(\mathrm{N})$;
5. $P$ : power, calculated from torque and rotational speed (W).

For the study on repeatability and when exploring statistical variation of parameters, additional measurements are included. Standard deviations are provided for vertical velocity, $W$; the remaining root bending moments, $\mathrm{RBM}_{1}$ \& $\mathrm{RBM}_{2}$; force in the streamwise direction measured by the 6DOF load cell, $F_{X}$; moment about $y$ from the 6DOF load cell, $M_{Y}$.

\subsection{Time domain}

\subsubsection{Time series}

The time-domain results for key environmental and turbine parameters, in the presence of both following and opposing waves, are presented in Fig. 4. The three repeats are shown for each case. It is apparent that there is a large increase in the fluctuations of the presented parameters for the opposing wave condition: the greatly increased surface elevations and corresponding wave-induced velocities result in a significant increase in the standard deviations of the measured turbine loads. The maximum measured wave height (mean over repeats) based on zero up-crossing time-domain analysis is equivalent to $9.63 \mathrm{~m}$ full-scale for the opposing case and only $2.83 \mathrm{~m}$ for the following condition. This highlights the magnitude of the wave-current interaction and indicates that the expected turbine loads will vary significantly over a tidal cycle with a constant input (boundary) environmental wave forcing condition.

Assessing the three repeats, it is evident that the repeatability is high for $\eta$, along with the rotor-averaged turbine parameters: $P$ and $T$. This is particularly the case for the opposing wave condition, due to the larger proportion of velocity fluctuations resulting from the deterministic wave condition, as opposed to random turbulence. Turbulence Intensity (T.I.) is approximately $7 \%$ in the FloWave tank for this flow velocity (Sutherland et al. 2017a). It is also apparent that slightly lower repeatability is observed for the flapwise RBM measurements than for thrust, which is due to the different relationships between blade angle and wave phase for the three sea state realisations.

\subsubsection{Observed maximum and minimum values}

To further explore the repeatability, and its influence on reliable identification of expected peak loads, the maximum and minimum measured values for an extended set of parameters have been calculated for all three repeats, and are presented in Table 3. These maxima and minima are taken after the time series have been low-pass filtered with a cutoff frequency of $4 \mathrm{~Hz}$ to remove the influence of sensor noise. Assessing the 
Fig. 4 Time-domain results of key environmental and turbine parameters for the opposing and following wave conditions. The three repeats of each conditions are shown for each parameter. The short time period shown is chosen to aid visibility and includes the point at which the largest wave is observed in the opposing sea state. The right hand axis shows values relative to the mean, whilst the left hand axis shows absolute values

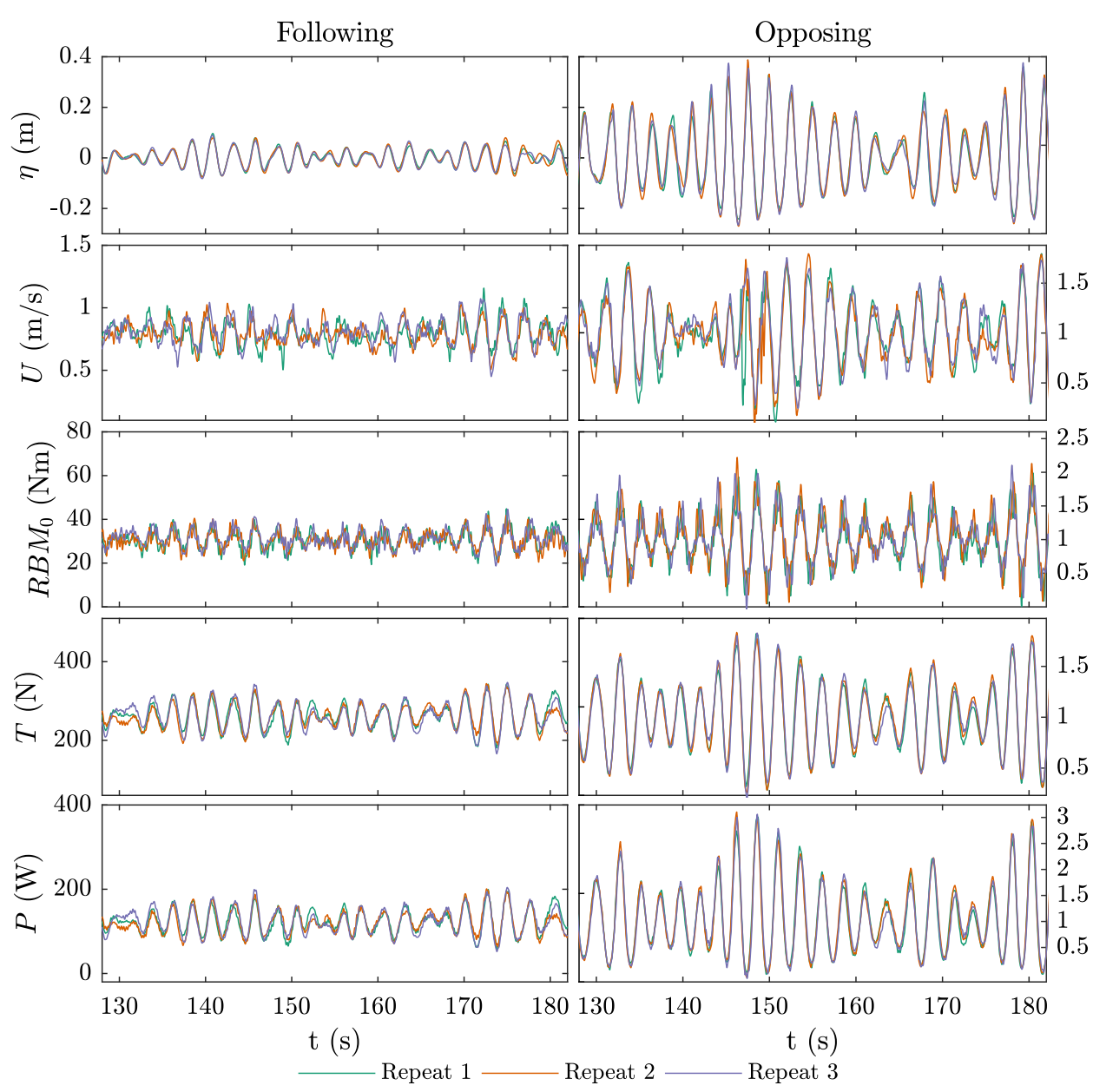

Table 3 Maximum and minimum values for a variety of environmental and turbine parameters for waves following and opposing the current

\begin{tabular}{llllll}
\hline Paramater & $\eta(\mathrm{m})$ & $U(\mathrm{~m} / \mathrm{s})$ & $W(\mathrm{~m} / \mathrm{s})$ & $\mathrm{RBM}_{0}(\mathrm{Nm})$ & $\mathrm{RBM}(\mathrm{Nm})$ \\
\hline Maximum (following) & $0.0995,0.0909,0.0985$ & $1.16,1.06,1.07$ & $0.255,0.253,0.267$ & $44.9,43,44.6$ & $42.2,40.3,39.5$ \\
Minimum (following) & $-0.0925,-0.076,-0.0819$ & $0.498,0.506,0.45$ & $-0.285,-0.319,-0.272$ & $17,18.3,18.7$ & $14.3,14.2,14.4$ \\
Maximum (opposing) & $0.361,0.388,0.376$ & $1.45,1.43,1.47$ & $0.558,0.599,0.583$ & $67.4,68.3,65.9$ & $64.3,60.3,64.5$ \\
Minimum (opposing) & $-0.264,-0.27,-0.266$ & $0.0862,0.0229,0.134$ & $-0.697,-0.636,-0.72$ & $0.00629,1.4,-1.9-3.89,-4.8,-2.6$ \\
\hline $\mathrm{RBM}_{2}(\mathrm{Nm})$ & $T(\mathrm{~N})$ & $F_{X}(\mathrm{~N})$ & $M_{Y}(\mathrm{Nm})$ & $P(\mathrm{~W})$ \\
\hline $42,42.1,42.5$ & $343,351,347$ & $366,370,364$ & $372,381,376$ & $200,210,204$ \\
$17.7,17.4,17.9$ & $180,173,166$ & $197,192,184$ & $197,195,183$ & $57.9,55.6,51.9$ \\
$65.7,66.4,67.5$ & $472,475,473$ & $483,480,487$ & $508,513,515$ & $371,383,378$ \\
$-1.04,-2.56,-6.35$ & $59.9,67.3,48.9$ & $90,91.4,81.2$ & $72.6,73.8,67.3$ & $-6.29,-9.25,-11.9$
\end{tabular}

Values for three repeats shown to three significant figures. Mean values are shown in Table 4 for reference

difference in maximum and minimum values obtained for the three repeats, it is evident that repeatability is reasonably high, indicating that the peak loads are dominated by the deterministic wave-induced velocities. Discrepancies are mostly a result of stochastic turbulent velocity fluctuations, and in the case of RBM values, additionally dependent on the aforementioned relationship between blade angle and wave phase.
Further assessing Table 3, it is evident that significantly larger maximum loads have been measured for the opposing wave case compared with the following. In addition, it is interesting to observe that negative RBM values are recorded for the opposing wave-current case, when the velocity is close to zero in the crest of a large wave. This does not correspond with a negative thrust as it is only occurs when a blade is close to the surface when a large opposing crest passes 

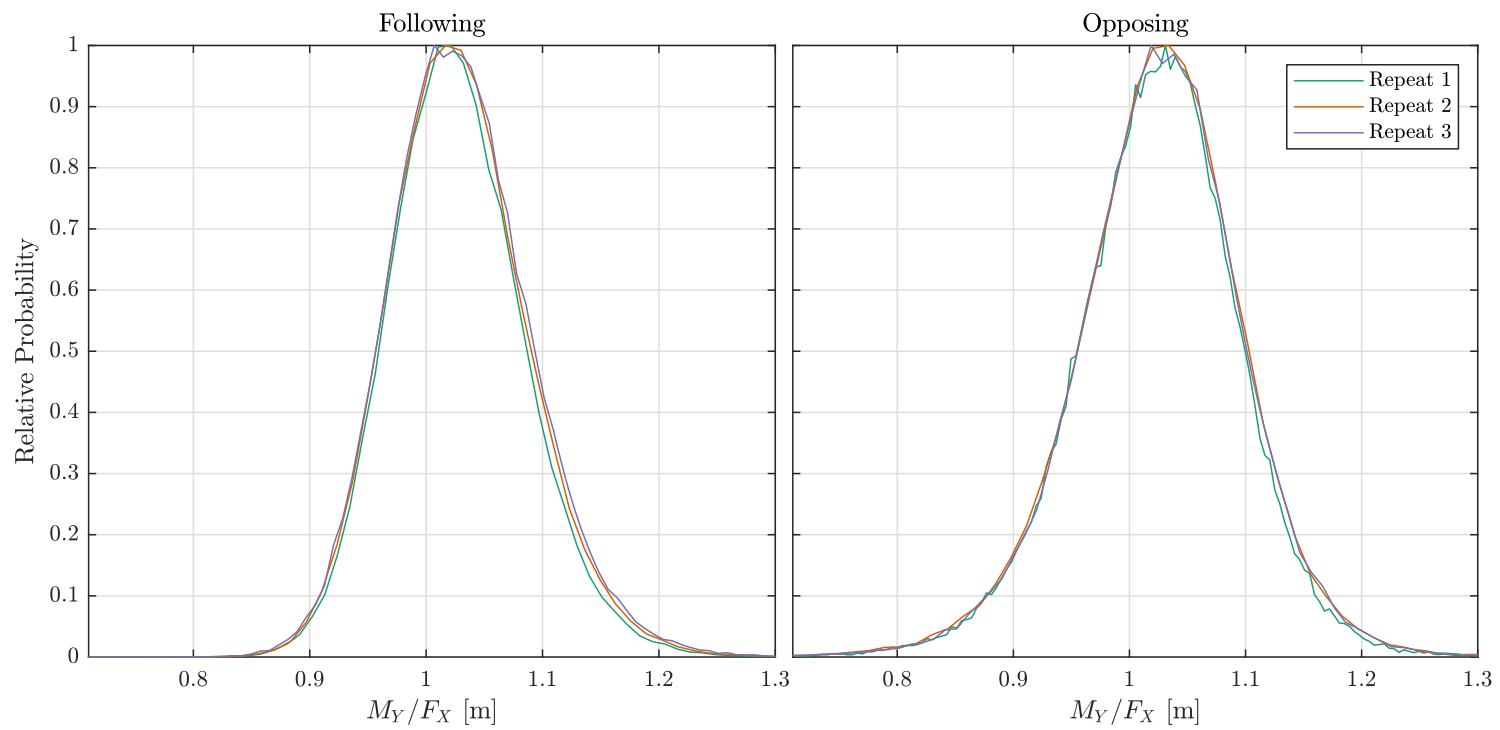

Fig. 5 Histograms for the centre of effort of $M_{Y}$ for three repeats of the following and opposing wave conditions

over, hence the sum of bending moments and rotor thrust always remains positive. This, however, is not the case for power (and torque) where negative values are observed for all three repeats of the opposing wave condition.

As noted in Sect. 2.2.1, the rotor behaviour is Reynolds independent above $0.6 \mathrm{~m} / \mathrm{s}$. Effectively, this means that all maximum values (including peak loads) reported in Table 3 are in this regime and can be considered representative. For the minimum values, however, caution is required. It is worth noting that the rotor-averaged minimum velocities will be somewhat larger than those presented in Table 3 due to the ADV position and vertical attenuation of waveinduced velocities. Considering this, the minimum velocities are still below $0.6 \mathrm{~m} / \mathrm{s}$ (approximately $0.52 \mathrm{~m} / \mathrm{s}$ and $0.39 \mathrm{~m} / \mathrm{s}$ at hub height for following and opposing, respectively) and hence the minimum values obtained for all turbine parameters cannot be seen as representative of a full-scale turbine. Fortunately, tidal turbine developers are largely interested in fatigue and peak loads.

\subsubsection{Assessing rotor-based vs tower-based measurements}

In the absence of waves, the mean value of $F_{X}$ (total structural load) is $12 \%$ larger than $T$ (rotor-based) owing to the additional drag on the tower. Assessing the mean peak loads (over three repeats) in waves, it can be seen that this drops to $5.7 \%$ in following waves and $2.1 \%$ for opposing waves. This is a result of two phenomena. The first is that the wave-induced velocities are larger at the top of the water column and hence the relative increase in load experienced by the rotor is larger than that of the tower. Secondly, the tower and rotor are in different $x$-positions and hence the peak velocities experienced by the rotor and tower will not occur at the same time.
This relative reduction in the observed $F_{X}$ value is more significant in opposing wave conditions as a result of the higher wavenumbers and increased velocity attenuation with depth.

The moment about the y-axis, $M_{Y}$, in the absence of waves, is ordinarily equivalent in magnitude to $F_{X}$ due to the rotor being $1 \mathrm{~m}$ from the tank floor $\left(M_{Y}\right.$ is approximately $2 \%$ higher due to current shear). Assessing the maximum values in Table 3, it is evident that the peak moments in waves are significantly larger than that of the measured peak thrust. This result is also due to the depth attenuation of wave-induced velocities resulting in the centre of effort of $M_{Y}$ acting above the rotor centre. This centre of effort can be calculated by computing the values of $\frac{M_{Y}}{F_{X}}$. Histograms of this for three repeats in the following and opposing wave condition are presented in Fig. 5. From this figure, it is clear that large variations in the centre of the effort of $M_{Y}$ are observed in both following and opposing wave conditions. When the centre of the effort is above the mean value (around 1-1.05 m), this corresponds to instants where the wave-induced velocity at the rotor is positive. The opposite is true for instants of negative wave-induced velocity. These large deviations in the centre of effort indicate that a considerable moment acts about the shaft, which will have significant implications for the loads on, and corresponding fatigue life of, the main shaft bearing.

\subsection{Frequency domain}

The frequency spectra of the key environmental and turbine parameters are presented in Fig. 6, showing the results for three repeats of the opposing and following wave cases. It is evident that all parameters have the largest energy density close to the frequency corresponding to the peak of the wave 

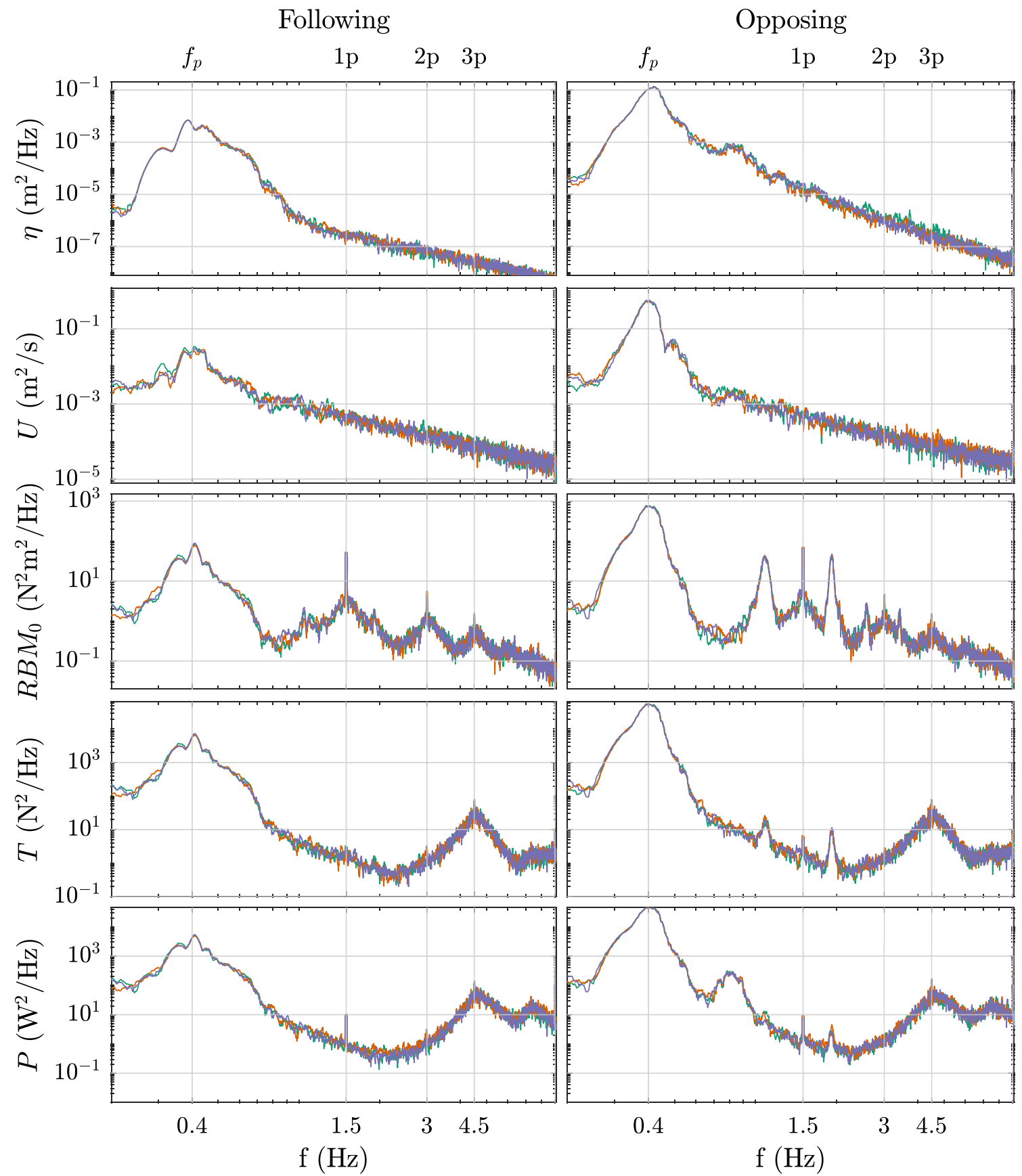

Repeat 1

Repeat $2 \longrightarrow$ Repeat 3

Fig. 6 Frequency domain results of key environmental and turbine parameters for the opposing and following wave conditions. The three repeats of both wave conditions are shown for each parameter. Grey lines denote the peak wave frequency $\left(f_{\mathrm{p}}=0.4 \mathrm{~Hz}\right)$ along with multiples of the rotational speed: $1 \mathrm{p}, 2 \mathrm{p}$ and $3 \mathrm{p}$ (as indicated on top axes) energy spectrum $(0.4 \mathrm{~Hz})$, and that the spectral magnitudes are, as expected, much larger for the opposing wave case. It is evident from the surface elevation spectra that there is a larger influence of wave reflections from the tank boundary for the following wave case, indicated by oscillations in the spectral magnitude. This is a result of the reflected waves opposing the current direction, thus increasing in amplitude, where the opposite effect occurs for the incident waves opposing the current.

A large peak at the rotational speed, $p$, is noted in the RBM spectra as a result of tower shadow and vertical shear effects. This is seen as a large peak at $3 p$ in the rotor-averaged turbine 


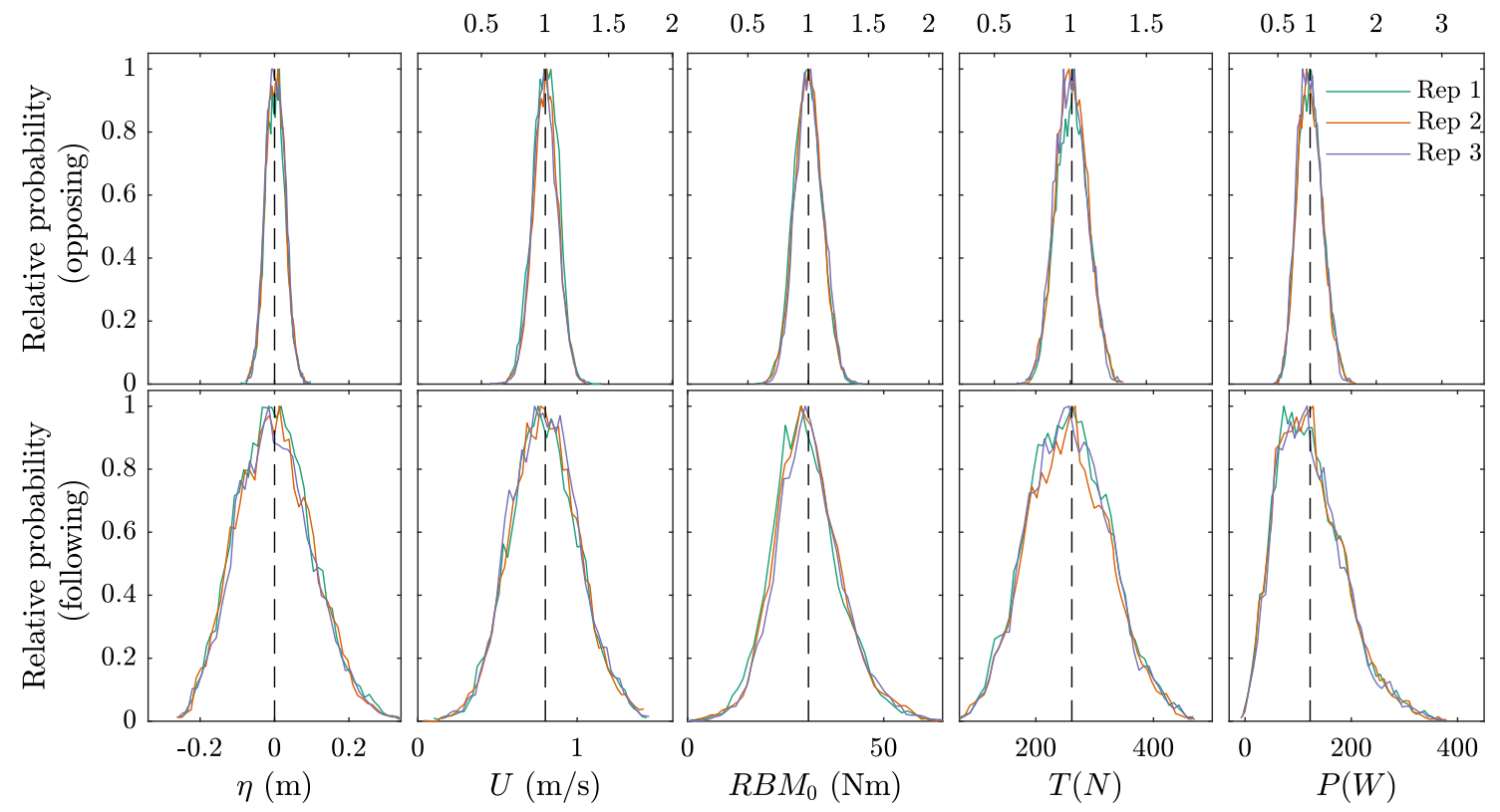

Fig. 7 Histograms of key environmental and turbine parameters for the opposing and following wave conditions. Three repeats for each wave case are shown. The black dotted line indicates the mean value calcu- lated over the three repeats. The top axis shows values relative to the mean, whilst the bottom axis shows absolute values

Table 4 Standard deviations and means of various environmental and turbine parameters for waves following and opposing the current, along with values without the presence of waves (approximate T.I. of 7\%)

\begin{tabular}{|c|c|c|c|c|c|c|c|c|c|c|}
\hline & $\eta(\mathrm{m})$ & $U(\mathrm{~m} / \mathrm{s})$ & $W(\mathrm{~m} / \mathrm{s})$ & $\mathrm{RBM}_{0}(\mathrm{Nm})$ & $\mathrm{RBM}_{1}(\mathrm{Nm})$ & $\mathrm{RBM}_{2}(\mathrm{Nm})$ & $T(\mathrm{~N})$ & $F_{X}(\mathrm{~N})$ & $M_{Y}(\mathrm{Nm})$ & $P(\mathrm{~W})$ \\
\hline \multicolumn{11}{|l|}{$\sigma$} \\
\hline Current only & - & 0.063 & 0.054 & 2.6 & 2.5 & 2.5 & 12 & 19 & 14 & 12 \\
\hline Following & 0.025 & 0.083 & 0.075 & 3.7 & 3.6 & 3.6 & 28 & 32 & 29 & 26 \\
\hline Opposing & 0.1 & 0.22 & 0.21 & 8.7 & 8.7 & 8.7 & 69 & 69 & 75 & 65 \\
\hline \multicolumn{11}{|l|}{$\mu$} \\
\hline Current only & - & 0.798 & -0.0496 & 30.8 & 27.5 & 29.6 & 259 & 275 & 283 & 123 \\
\hline Following & 0 & 0.800 & -0.0437 & 30.8 & 27.8 & 29.9 & 261 & 278 & 285 & 122 \\
\hline Opposing & 0 & 0.796 & -0.0556 & 30.7 & 27.2 & 29.4 & 256 & 273 & 280 & 124 \\
\hline
\end{tabular}

power and thrust spectra. Also noticeable in the RBM spectra are peaks at multiples of the rotational speed plus and minus the wave frequencies. This is a rotational sampling effect, introduced as the blades 'sample' the wave-induced velocity shear, and is much more significant for the opposing case due to the increased velocity magnitude and increased wavenumber (hence increased vertical wave-induced shear). They have also previously been noted in Gaurier et al. (2013) for regular wave conditions, but were not explained. This effect, whilst apparent in the rotor-based thrust measurements, is greatly reduced as the effect is averaged over all three blades. This is discussed further in Sect. 4.3.

The frequency spectrum of the turbine power for the opposing case shows a second peak corresponding to the peak wave frequency at around $0.8 \mathrm{~Hz}$. This is a result of the cubic relationship between power and velocity, meaning that, under assumptions of linear wave theory, peaks in the power spectrum will exist up to three times the wave frequencies with decreasing magnitude. For this opposing sea state condition, the third harmonic peak is not appreciable.

Comparing the spectra between the three repeats, it is evident that the frequency domain response is very repeatable, including the RBM measurements which were noted to have poor repeatability in the time domain. The repeatability of these spectral values support the logic that the poor timedomain repeatability is a result of the differing relationships between blade angle and wave phase between repeats. 


\subsection{TST load variations for opposing and following waves}

To assess the implications of the results presented in Sects. 3.1 and 3.2, statistical analysis of the TST load measurements was conducted. Histograms of the main environmental and turbine parameters are presented in Fig. 7. As already indicated by Figs. 4 and 6, significantly larger variations in loads are expected for the opposing conditions. The corresponding standard deviations of the parameters in Fig. 7, plus the extended set (including additional RBM sensors and 6DOF load cell measurement), are presented in Table 4, along with the corresponding mean values over the three repeats. Assessing the mean values, it is evident that the presence of the irregular wave conditions (following or opposing) does not serve to significantly alter the mean values of the loads recorded. This suggests that the turbine performance is also unaltered and that mean values of $C_{\mathrm{p}}$ and $C_{\mathrm{t}}$ in waves can be effectively calculated using the mean kinetic inflow.

Load variations in opposing waves are significantly larger than in following waves, with standard deviation values for opposing wave conditions ranging between 215 and 260\% of the equivalents in following waves. When comparing the opposing wave condition to current-only measurements, this range increased to between 340 and $565 \%$ currentonly equivalents depending on the parameter being assessed. These higher standard deviations have significant implications for the fatigue of blades and other components and will impact the TST electro-mechanical control strategies. The associated increase in the expected maximum loads will also affect the requirements for structural design.

\subsubsection{Extreme distributions of thrust}

To further assess the peak values, extreme value distributions of the measured thrust are presented in Figs. 8 and 9 for the following and opposing wave conditions, respectively. Distributions were fitted to the relative thrust $\left(T / T_{0}\right.$ where $T_{0}$ is the mean thrust) over a certain threshold. Leadbetter (1983) showed that a generalised Pareto distribution (GPD) should be applied to threshold derived extreme data, and hence a GPD was fitted to the measured data for each test. The threshold was set to $85 \%$ of the peak thrust measured for the first repeat of each wave condition. The return periods for these plots are shown in "realisations", where one realisation is $512 \mathrm{~s}$ (tank scale) of the specified wave-current condition. They can be scaled to account for the amount of time exposed to the condition, or converted to full-scale probabilities.

Although generally a good match, some discrepancy between the GPD fit and the measured data is noted for the third repeat of the opposing wave condition. It is concluded, however, that due to the peculiar shape of the measured distribution, an alternative distribution choice would not have been able to reduce this discrepancy significantly. The resulting return periods between repeats remain consistent.

It is evident from Figs. 8 and 9 that the extreme values of thrust expected in the opposing wave condition are much larger than in the equivalent following wave condition. For example, the expected thrust value for 100 realisations of the opposing condition is around 1.95 times the mean thrust, where for the following condition this value is only around 1.4. Also notable from the distributions is that a thrust exceeding 1.75 times the mean thrust is expected to occur over 100 times in each realisation of the opposing wave condition. This value of thrust is not expected to be reached in the following case, regardless of the number of realisations carried out (i.e. length of time exposed to this condition). This further emphasises the significant difference in operating conditions and resulting loads experienced by a tidal turbine in opposing and following wave conditions of equivalent open-ocean parameters.

\section{Discussion}

\subsection{Comparison between opposing and following waves}

The results presented in this paper show the large variation in wave parameters and turbine loads expected over a tidal cycle with the same open-ocean wave condition. This has a number of implications. The large variations observed indicate that it is important to understand and de-risk TST devices in the presence of waves both following and opposing the current. For the turbine model and sea state presented, the opposing wave conditions induced much larger loads on the device. In general, this will be the case for turbines with the rotor located around mid-depth or higher in the water column, or when waves feature large amplitudes with high periods. However, devices installed much lower in the water column may be unaffected by many wave conditions opposing the current as the higher wavenumbers will cause the wave-induced velocities to attenuate at a greater rate with depth. For this scenario, the following conditions (with lower wavenumbers) may result in the penetration of the wave-induced velocities to the depth of the turbine rotor and hence may be the wave-current combinations associated with the largest waveinduced loads. The nature of the loading is hence driven by a combination of key turbine and channel dimensions, turbine control strategy, sea state and current velocity, and TST devices should be assessed in the likely range they are expected to operate within. 


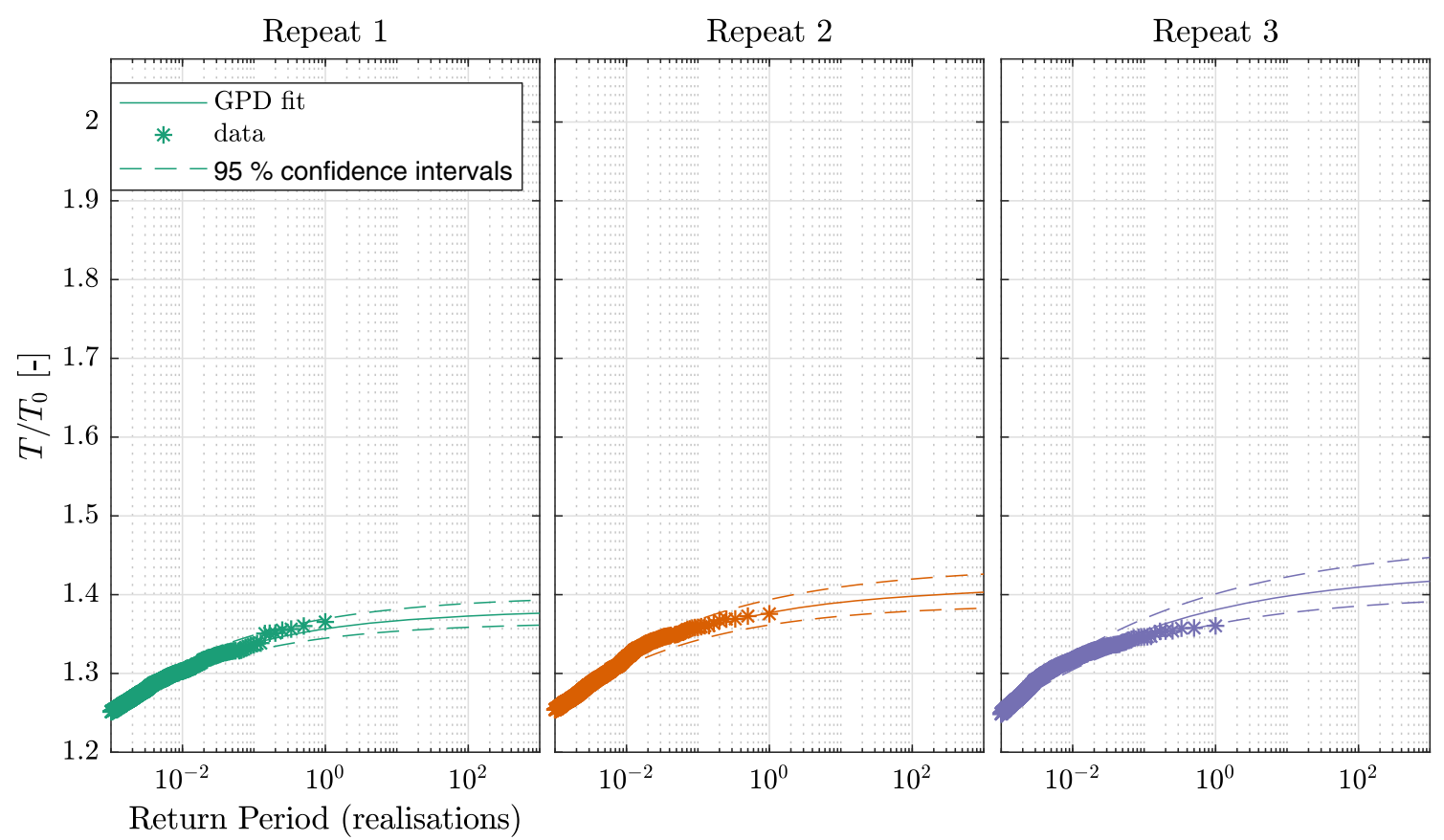

Fig. 8 Extreme distributions of thrust in the following wave condition obtained using a generalised Pareto distribution. One distribution for each repeat is shown
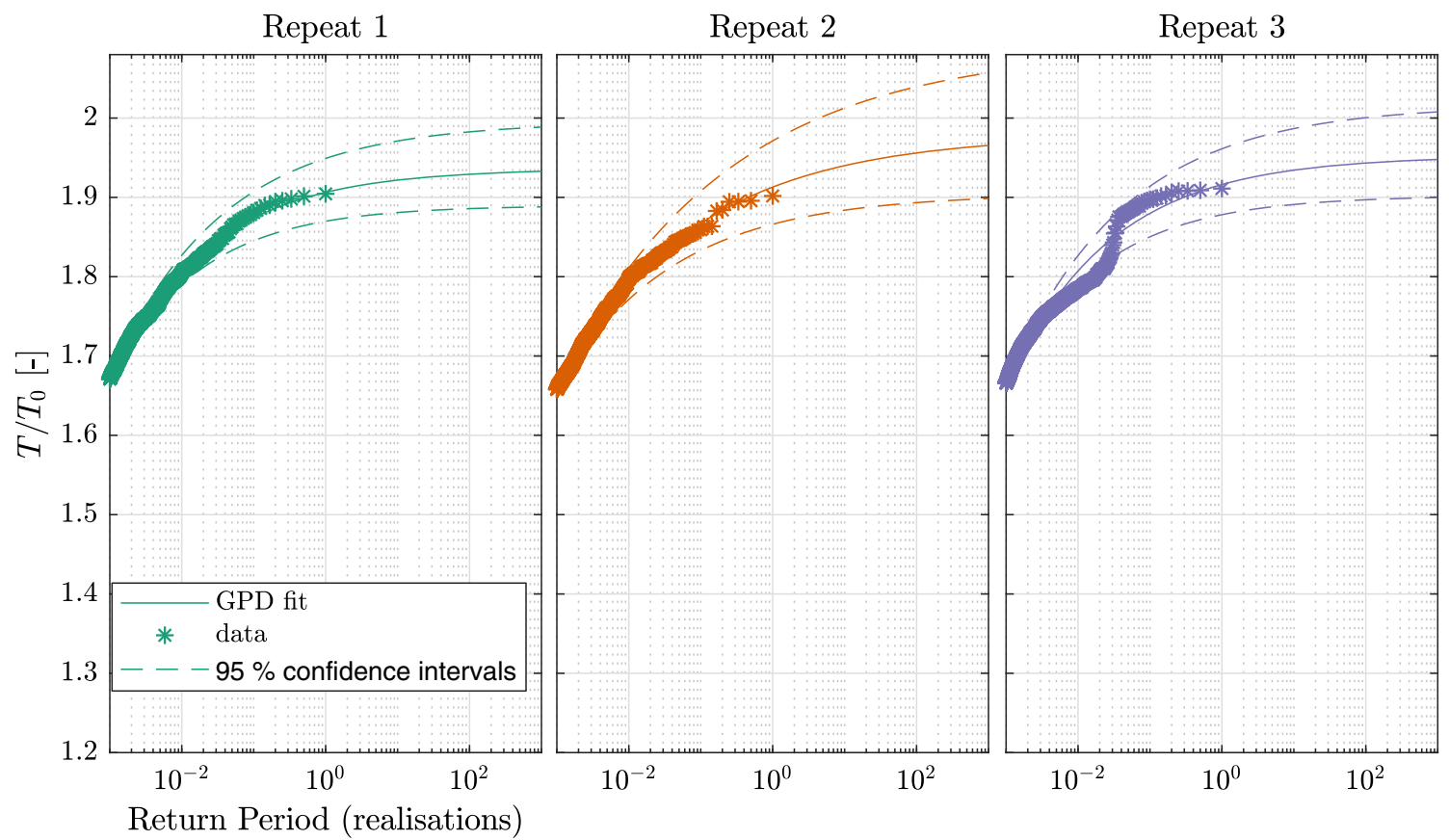

Fig. 9 Extreme distributions of thrust in the opposing wave condition obtained using a generalised Pareto distribution. One distribution for each repeat is shown

\subsection{Understanding the wave-current conditions at a site}

The large differences in the measured wave heights and wave-induced velocities for the following and opposing conditions highlight the requirement to understand the combined wave-current environment. This suggests that coupled wavecurrent models of sites of interest [e.g. Guillou (2017), Venugopal et al. (2017)] and/or extensive measurement programmes should be used to properly understand the nature of the conditions that a TST device must be able to operate within. Contrary to this, however, is the finding that the wave- 
current interaction theory presented appeared to match well with measured data (Table 2 and Fig. 3), suggesting that separate knowledge of open-ocean wave conditions and expected current velocities may be used to get approximate estimates of the expected 'in-channel' range of conditions for use in numerical models or tank tests. However, it is noted that only a small sample size is validated in this paper. Additionally, it is evident that the theory presented will be insufficient in capturing some of the more complex wave-current conditions, including waves interacting with spatially and temporally varying currents, as frequently observed in site data (Sutherland et al. 2017b).

\subsection{Rotational sampling of wave-induced velocities}

As noted in Sect. 3.2, interesting side-band frequencies are apparent in the blade root bending moment spectra at multiples of the rotational speed plus and minus the wave frequencies due to rotational sampling of wave-induced velocities. The effect is extremely large for the opposing wave condition and negligible for the following case, highlighting the wavenumber dependency, effectively depending on the difference in wave-induced velocity observed over the rotor plane. The positive and negative sidebands result from the apparent wave frequencies observed in the reference frame of the blade, and is equivalent to a more complex version of amplitude modulation.

For the opposing wave condition, the magnitude of the load variations associated with the rotational sampling effects are many times larger than that of the tower shadow and shear combined. When there is significant difference in waveinduced velocity over the rotor (function of rotor position \& size, wave height and wavenumbers), this effect clearly has implications for the design and lifetime of blades. As these are high-frequency load variations they may be important contributors to fatigue for tidal turbines installed in exposed sites. Future work will explore this further and create a tool able to predict the magnitude of these side-band loads and subsequent consequences.

\subsection{Comparison to previous results with turbine model}

A number of previous studies have been carried out with the turbine model used in this current study. In the absence of waves, baseline measurements of $C_{\mathrm{P}}$ and $C_{\mathrm{T}}$ are presented in Payne et al. (2017), and a study on the frequency and angular dependence of the loading is available in Payne et al. (2018). Studies with waves have also been carried out including a thorough assessment in a wide range of regular waves (Draycott et al. 2019a) and the effect of oblique regular waves and currents (Martinez et al. 2018). The effect of focused wave groups on turbine loads is further reported in Draycott et al. (2019b).

It is somewhat difficult to quantitatively compare the results in irregular waves to those obtained without waves, and in the presence of regular waves or focused groups, due to the difference of conditions \& test facilities used (in some cases) and uncertainty of instantaneous velocities at the rotor. Some conclusions can, however, be made by comparison between these studies. One of these is that the general spectral form (location and relative size of rotation-based peaks and wave-induced peaks) are in agreement. Peaks at multiples of the rotational speed in the RBM spectra are apparent in Draycott et al. (2019b) and explored in detail in Payne et al. (2018). What is not observed in either of these studies is the side-band frequencies discussed in Sect. 4.3. This is despite the fact that the results presented in Draycott et al. (2019b) are associated with focused irregular wave conditions of equal peak frequency. The authors suspect there are two reasons for this phenomenon only being present in the current study. The first is that the effect is only obvious for the opposing wave condition (although visible for the following case) due to the higher wavenumbers and greater wave-induced velocity shear, and Draycott et al. (2019b) only presents focused waves following the current. The second is that the test lengths were very short in the previous study, resulting in larger frequency bins in the spectral analysis. This means that a larger proportion of the energy density is associated with turbulence in each bin, hence making the side bands not visible.

Comparison to Draycott et al. (2019a) provides some context to the wave-induced loads presented in this paper. In Draycott et al. (2019a), the turbine is assessed in a wide range of regular waves, of various frequencies and amplitudes, both following and opposing the current. A simple model based on psuedo-stationarity is used for comparison and provides reasonable results. In particular, good agreement is found for conditions with smaller wave amplitudes, or those which follow the current direction. In relation to the current study, it can therefore be inferred that dynamic effects are likely to be minimal for the following wave conditions. Due to increased model errors observed in Draycott et al. (2019a) for larger, opposing, waves, the same cannot be inferred for the opposing wave condition presented in this manuscript. As mentioned in Sect. 3.1, the results for the lowest velocities are likely to be unrepresentative due to no longer being in the same Reynolds regime $\left(C_{\mathrm{P}}\right.$ and $C_{\mathrm{T}}$ altered), and as such caution is required for minimum values of power and thrust. Peak values, however, are likely to be representative of those experienced in analogous fullscale conditions. This does not preclude the possibility that dynamic stall may be occurring for the largest wave-induced velocities. Although it is difficult to elucidate these effects from the study itself due to uncertainty in the instantaneous 
flow velocity, it may be inferred that the likely effects are small due to the high $\lambda$ value used in this study, and the relatively small error observed in Draycott et al. (2019a). To properly quantify this effect, future test campaigns will reduce the $\lambda$ value and devise a more sophisticated instrumentation setup to study the influence of dynamic stall in large wave conditions. Models incorporating dynamic stall (e.g. Scarlett et al. 2018) will be used to increase insight into the phenomena.

\section{Conclusions}

In this paper, we have presented the experimental results of a scale model tidal turbine subject to irregular wave conditions with current. In a combined wave-current test facility, a constant open-ocean wave condition was simulated both following and opposing the current to assess the expected variation in environmental parameters and turbine loads over a typical tidal cycle. Measured wave heights were found to be nearly four times larger when opposing the current, with the resulting standard deviations of all measured turbine parameters being over twice as large in the opposing case. Mean values appear to be unaltered by the presence of waves. The results presented demonstrate the significant changes in conditions that tidal turbines must operate in as a result of varying wave-current interaction over a tidal cycle. The requirement to understand the combined wave-current environment is highlighted along with the necessity to de-risk the operation of tidal turbines in such dynamic conditions. Additionally, the temporal, spectral and statistical outputs presented provide new insight into the nature of loads experienced by tidal turbines subject to irregular waves and fast currents.

Acknowledgements The authors are grateful for the financial support from the UK Engineering and Physical Sciences Research Council through FloWTurb: Response of Tidal Energy Converters to Combined Tidal Flow, Waves and Turbulence (EP/N021487/1) and SuperGen UK Centre for Marine Energy Research (EP/M014738/1). The authors also acknowledge support from the EPSRC for funding the FloWave Ocean Energy Research facility (EP/I02932X/1). The authors are extremely grateful to the staff at the FloWave facility, in addition to the FloWTurb project team, for making this research possible.

Open Access This article is distributed under the terms of the Creative Commons Attribution 4.0 International License (http://creativecomm ons.org/licenses/by/4.0/), which permits unrestricted use, distribution, and reproduction in any medium, provided you give appropriate credit to the original author(s) and the source, provide a link to the Creative Commons license, and indicate if changes were made.

\section{References}

Barltrop N, Varyani KS, Grant A, Clelland D, Pham X (2006) Wavecurrent interactions in marine current turbines. Proc Inst Mech Eng
Part M J Eng Marit Environ 220(4):195-203. https://doi.org/10. 1243/14750902JEME45

Chakrabarti SK, Johnson JG (1995) Random wave-current interaction-theory and experiment. No CONF-950695American Society of Mechanical Engineers, New York, NY (United States)

De Jesus Henriques TA, Tedds SC, Botsari A, Najafian G, Hedges TS, Sutcliffe CJ, Owen I, Poole RJ (2014) The effects of wave-current interaction on the performance of a model horizontal axis tidal turbine. Int J Mar Energy 8:17-35. https://doi.org/10.1016/j.ijome. 2014.10.002

Draycott S, Davey T, Ingram DM, Day A, Johanning L (2016) The SPAIR method: isolating incident and reflected directional wave spectra in multidirectional wave basins. Coast Eng 114:265-283. https://doi.org/10.1016/j.coastaleng.2016.04.012

Draycott S, Steynor J, Davey T, Ingram DM (2018) Isolating incident and reflected wave spectra in the presence of current. Coast Eng J $1-12$

Draycott S, Nambiar A, Sellar B, Davey T, Venugopal V (2019a) Assessing extreme loads on a tidal turbine using focused wave groups in energetic currents. Renew Energy 135:1013-1024. https://doi.org/ 10.1016/j.renene.2018.12.075

Draycott S, Nambiar A, Sellar B, Davey T, Venugopal V (2019b) Assessing extreme loads on a tidal turbine using focused wave groups in energetic currents. Renew Energy 135:1013-1024. https://doi.org/10.1016/j.renene.2018.12.075

Faudot C, Dahlhaug OG (2012) Prediction of wave loads on tidal turbine blades. Energy Proc 20:116-133. https://doi.org/10.1016/j. egypro.2012.03.014

Galloway PW, Myers LE, Bahaj AS (2014) Quantifying wave and yaw effects on a scale tidal stream turbine. Renew Energy 63(2014):297-307. https://doi.org/10.1016/j.renene.2013.09.030

Gaurier B, Davies P, Deuff A, Germain G (2013) Flume tank characterization of marine current turbine blade behaviour under current and wave loading. Renew. Energy 59:1-12. https://doi.org/10.1016/j. renene.2013.02.026

Guillou N (2017) Modelling effects of tidal currents on waves at a tidal stream energy site. Renew Energy 114:180-190. https://doi.org/ 10.1016/j.renene.2016.12.031

Guo X, Yang J, Gao Z, Moan T, Lu H (2018) The surface wave effects on the performance and the loading of a tidal turbine. Ocean Eng 156(May):120-134. https://doi.org/10.1016/j.oceaneng.2018.02. 033

Hashemi MR, Grilli ST, Neill SP (2016) A simplified method to estimate tidal current effects on the ocean wave power resource. Renew Energy 96:257-269. https://doi.org/10.1016/j. renene.2016.04.073

Heller V (2011) Scale effects in physical hydraulic engineering models. J Hydraul Res 49(3):293-306. https://doi.org/10.1080/00221686. 2011.578914

IEC TS 62600-200:2013 (2013) Marine energy-wave, tidal and other water current converters. Part 200: electricity producing tidal energy converters-power performance assessment. Standard, International Electrotechnical Commission, Geneva, Switzerland

IEC TS 62600-201:2015 (2015) Marine energy-wave, tidal and other water current converters. Part 201: tidal energy resource assessment and characterization. Standard, International Electrotechnical Commission, Geneva, Switzerland

Jonsson IG (1990) Wave-current interactions. In: Le Mehaute B, Hanes DM (eds) The sea, ocean engineering science, vol 9, chap 7. WileyInterscience Publications, New York, pp 65-120

Leadbetter MR (1983) Extremes and local dependence in stationary sequences. Zeitschrift für Wahrscheinlichkeitstheorie und Verwandte Gebiete 65(2):291-306. https://doi.org/10.1007/ BF00532484 
Lust EE, Luznik L, Flack KA, Walker JM, Van Benthem MC (2013) The influence of surface gravity waves on marine current turbine performance. Int J Mar Energy 3-4:27-40. https://doi.org/10.1016/j. ijome.2013.11.003

Luznik L, Flack KA, Lust EE, Taylor K (2013) The effect of surface waves on the performance characteristics of a model tidal turbine. Renew Energy 58:108-114. https://doi.org/10.1016/j. renene.2013.02.022

MacEnri J, Reed M, Thiringer T (2013) Influence of tidal parameters on SeaGen flicker performance. Philos Trans R Soc Lond A Math Phys Eng Sci 371(1985):20120247. https://doi.org/10.1098/rsta. 2012.0247

Martinez R, Payne GS, Bruce T (2018) The effects of oblique waves and currents on the loadings and performance of tidal turbines. Ocean Eng 164:55-64. https://doi.org/10.1016/j.oceaneng.2018.05.057

McNaughton J, Harper S, Sinclair R, Sellar B (2015) Measuring and modelling the power curve of a commercial-scale tidal turbine. In: Proceedings of 11th european wave and tidal energy conference. Nantes, France

MeyGen Ltd (2016) MeyGen Tidal Energy Project Phase 1. Project Environmental Monitoring Programme, Technical Report. Tech. Rep. MEY-1A-70-HSE-018-I-PEMP

Milne IA, Sharma RN, Flay RGJ, Bickerton S (2010) The role of waves on tidal turbine unsteady blade loading. In: Proceedings of the $3 \mathrm{rd}$ international conference on ocean energy, Bilbao, Spain, pp 1-6

Milne IA, Sharma RN, Flay RGJ (2017) The structure of turbulence in a rapid tidal flow. Proc R Soc Lond A Math Phys Eng Sci 473(2204). https://doi.org/10.1098/rspa.2017.0295, http://rspa. royalsocietypublishing.org/content/473/2204/20170295.full.pdf

Moreira RM, Peregrine DH (2012) Nonlinear interactions between deep-water waves and currents. J Fluid Mech 691:1-25. https:// doi.org/10.1017/jfm.2011.436

Mullings HR, Stallard T, Payne GS (2017) Operational loads on a tidal turbine due to environmental conditions. In: Proceedings of the 12th European Wave and Tidal Energy Conference, Cork, Ireland

New Civil Engineer (2019) The MeyGen Tidal Scheme Project. https:// www.newcivilengineer.com/world-view/future- of-energycatching-the-flow/10038276.article. Accessed 20 Feb 2019

Noble DR, Davey T, Smith HCM, Kaklis P, Robinson A, Bruce T (2015) Characterisation of spatial variation in currents generated in the flowave ocean energy research facility. In: Proceedings of the 11th European wave and tidal energy conference, Nantes, France, pp $1-8$

Ordonez-Sanchez S, Allmark M, Porter K, Ellis R, Lloyd C, O’Doherty T, Johnstone C (2019) Analysis of a horizontal axis tidal turbine performance in the presence of regular and irregular waves using two control strategies. J Mar Sci Eng 12:367. https://doi.org/10. 3390/en12030367

Parkinson SG, Collier WJ (2016) Model validation of hydrodynamic loads and performance of a full-scale tidal turbine using Tidal Bladed. Int J Mar Energy 16:279-297. https://doi.org/10.1016/j. ijome.2016.08.001
Payne GS, Stallard T, Martinez R (2017) Design and manufacture of a bed supported tidal turbine model for blade and shaft load measurement in turbulent flow and waves. Renew Energy 107:312-326. https://doi.org/10.1016/j.renene.2017.01.068

Payne GS, Stallard T, Martinez R, Bruce T (2018) Variation of loads on a three-bladed horizontal axis tidal turbine with frequency and blade position. J Fluids Struct 83(November):156-170. https://doi. org/10.1016/j.jfluidstructs.2018.08.010

Scarlett GT, Bremer TVD, Sellar B, Viola IM (2018) Unsteady hydrodynamics of full-scale tidal turbines. 6th Oxford Tidal Energy Workshop (March)

Sellar B, Wakelam G, Sutherland DRJ, Ingram DM, Venugopal V (2018) Characterisation of tidal flows at the european marine energy centre in the absence of ocean waves. Energies 11(1):176. https://doi.org/10.3390/en11010176, http://www. mdpi.com/1996-1073/11/1/176

Sos M, Johnston L, Walker J, Rahimian M (2017) The Impact of waves and immersion depth on horizontal axis tidal turbine performance. In: European wave and tidal energy conference, Cork, Ireland, pp 1-8, http://www.albayan.ae

Stallard T, Collings R, Feng T, Whelan J (2013) Interactions betweem tidal turbine wakes: experimental study of a group of 3-bladed rotors. Philos Trans R Soc Lond A 371(1985):1471-2962

Sutherland DRJ, Noble DR, Steynor J, Davey TAD, Bruce T (2017a) Characterisation of current and turbulence in the flowave ocean energy research facility. Ocean Eng 139:103-115. https://doi.org/ 10.1016/j.oceaneng.2017.02.028

Sutherland DRJ, Sellar BG, Venugopal V, Borthwick AGL (2017b) Effects of spatial variation and surface waves on tidal site characterisation. In: Proceedings of the 12th European Wave and Tidal Energy Conference. Cork, Ireland

Venugopal V, Nemalidinne R (2015) Wave resource assessment for Scottish waters using a large scale North Atlantic spectral wave model. Renew Energy 76:503-525. https://doi.org/10.1016/ j.renene.2014.11.056

Venugopal V, Sellar B, Sutherland D, Borthwick A, Wakelam G (2017) Numerical modelling of combined wave, tidal current and turbulence interaction at tidal energy sites in the fall of warness, Scotland. In: Proceedings of the 12th European Wave and Tidal Energy Conference, Cork, Ireland

Walker S, Cappietti L (2017) Experimental studies of turbulent intensity around a tidal turbine support structure. Energies 10(4):1-21. https://doi.org/10.3390/en10040497

Whelan JI, Stallard TJ (2011) Arguments for modifying the geometry of a scale model rotor. In: Proceedings of the 9th European Wave and Tidal Energy Conference, Southampton, UK

Publisher's Note Springer Nature remains neutral with regard to jurisdictional claims in published maps and institutional affiliations. 